\title{
Tsafon
}

Revue d'études juives du Nord

$80 \mid 2020$

Varia

\section{Thiery Laurent, Le Livre des 9000 déportés de France à Mittelbau-Dora}

\section{Monique Heddebaut}

\section{(2) OpenEdition}

1 Journals

\section{Édition électronique}

URL : https://journals.openedition.org/tsafon/3466

DOI : $10.4000 /$ tsafon.3466

ISSN : 2609-6420

Éditeur

Association Jean-Marie Delmaire

\section{Édition imprimée}

Date de publication : 1 décembre 2020

Pagination : 182-183

ISSN : 1149-6630

\section{Référence électronique}

Monique Heddebaut, "Thiery Laurent, Le Livre des 9000 déportés de France à Mittelbau-Dora », Tsafon

[En ligne], 80 | 2020, mis en ligne le 01 décembre 2020, consulté le 24 juin 2021. URL : http:// journals.openedition.org/tsafon/3466 ; DOI : https://doi.org/10.4000/tsafon.3466

Ce document a été généré automatiquement le 24 juin 2021.

Tsafon. Revues d'études juives du Nord 


\title{
Thiery Laurent, Le Livre des 9000 déportés de France à Mittelbau-Dora
}

\author{
Monique Heddebaut
}

\section{RÉFÉRENCE}

Thiery Laurent (sous la direction de), Le Livre des 9000 déportés de France à MittelbauDora, (préface d'Aurélie Filippetti), Paris, Éditions du Cherche Midi, 2500 p, 3000 photos, 2020, $49 €$.

1 Laurent Thiery, docteur en histoire, auteur d'une thèse sur La répression allemande dans le Nord/Pas-de-Calais, "zone rattachée » au Militärbefehlshaber in Belgien und Nordfrankreich: 1940-1944, est attaché au musée et centre d'histoire de La Coupole à Helfaut-Wizernes (Pas-de-Calais). C'est l'un des principaux équipements muséographiques du nord de la France pour la Seconde Guerre mondiale, installé depuis 1997 dans un immense bunker construit par l'Organisation Todt en 1943-1944.

2 Il a piloté ce projet européen qui a abouti, après deux décennies de recherches, à la publication du Livre des 9000 déportés de France à Mittelbau-Dora. Pas moins de soixanteneuf auteurs ont rédigé les notices de chacun des déportés français ou arrêtés en France et déportés au camp allemand de Dora, proche de Buchenwald auquel il était d'abord rattaché, depuis Abada Roger résistant communiste jusqu'à Zyman Benjamin, membre de l'Organisation Juive de Combat, en passant par Stéphane Hessel et Simone Veil.

60000 personnes furent envoyées dans ce camp et 8971 - parmi lesquelles au moins 550 étrangers - à partir de la France qui est la troisième nation la plus touchée. Une centaine de Juifs déportés dans les convois de la Solution finale a été immatriculée à Mittelbau-Dora. $60 \%$ des déportés de France y sont décédés ou peu après la Libération. On estime à seulement 4000 le nombre de retours. Les déportés ont été utilisés, entre août 1943 à avril 1945, comme main-d'œuvre pour creuser des tunnels, installer un site industriel et assembler les pièces des missiles balistiques, les V2, qui étaient censés être 
lancés depuis le nord de la France, depuis le bunker fortifié d'Helfaut-Wizernes, pour bombarder l'Angleterre et Londres. Les conditions sur place, exécrables, en font l'un des camps de concentration les plus meurtriers.

4 Environ 200 personnes étaient originaires du Nord/Pas-de-Calais. Vingt-deux Tsiganes du Nord sur les 352 déportés du convoi Z du 15 janvier 1944 y figurent. Dora ne compte qu'un seul juif nordiste, Nathan Alpern. Celui-ci, commerçant à Lens (Pas-de-Calais), est arrêté le 11 septembre 1942 à son domicile par la Feldgendarmerie, avec ses parents, lors de la grande rafle des juifs du Nord-Pas-de-Calais. Passé par la gare de Lille-Fives, puis le camp de Malines (Belgique), il est déporté par le convoi X du 15 septembre 1942 à Auschwitz-Birkenau qui compte 513 personnes arrêtées dans le nord de la France. Ses parents sont gazés à l'arrivée comme $68 \%$ des 1047 personnes de ce convoi. Il est sélectionné pour le travail. Il est envoyé au Revier [infirmerie] de Monowitz entre le 7 décembre 1943 et le 12 avril 1944. Il est ensuite transféré au camp de Mittelbau-Dora le 18 janvier 1945 en raison de l'avancée de l'Armée rouge. Jugé encore une fois apte au travail, il est affecté le 5 février au Kommando d'Ellrich jusqu'à l'évacuation de ce camp le 4 avril 1945. Nathan Alpern est ensuite transféré au camp de Bergen-Belsen qui est surpeuplé, puis dirigé vers d'anciennes casernes SS de la ville. Libéré le 15 avril 1945 par les troupes britanniques, il est rapatrié en France à la fin de ce mois.

La Coupole 62504 Saint-Omer cedex France, 0321122727

6 https://www.lacoupole-france.com/ 